\title{
Pseudocholangiocarcinoma Sign: Management of Portal Cavernoma Biliopathy with Fully-Covered Self-Expandable Metal Stent
}

\author{
Luís C Lourenço ${ }^{1}$, David V Horta ${ }^{1}$, Catarina G Rodrigues ${ }^{1}$, Jorge Canena ${ }^{1,2}$ and Jorge Reis ${ }^{1}$ \\ ${ }^{1}$ Department of Gastroenterology, Hospital Professor Doutor Fernando Fonseca, Amadora, ${ }^{2}$ Center of Gastroenterology, Cuf Infante Santo \\ Hospital-Nova Medical School/Faculty of Medical Sciences, Lisbon, Portugal
}

Benign bile duct strictures are commonly caused by stones, bile duct injury, sclerosing cholangitis, chronic pancreatitis, and congenital abnormalities. Bile duct changes caused by portal hypertension represent another group of uncommon causes of benign stricture.

The earliest evidence of portal biliopathy was described by Hunt in 1965. ${ }^{1}$ Portal cavernoma biliopathy (PCB) is a rare condition caused by cavernomatous transformation of an extra-hepatic portal vein thrombosis (EHPVT). It is rarely symptomatic; however, due to compression of the biliary tree, it can result in biliary obstruction, choledocholithiasis, jaundice, and cholangitis.

Endoscopic therapy for symptomatic PCB is a matter of discussion since this condition is rare. ${ }^{2}$

We present a rare case of symptomatic $\mathrm{PCB}$ with a common bile duct (CBD) stricture, refractory to conventional endoscopic therapy in a patient unfit for surgery. Owing to the risk of repeated plastic stent exchange, we chose a more definite endoscopic approach with temporary placement of fully-covered self-expandable metal stent (fCSEMS). In this paper, we also report our successful results following application of fcSEMS.

An 82-year-old man presented to our hospital with fever, right-upper quadrant abdominal pain, and jaundice. He had

Received: July 25, 2016 Revised: October 12, 2016

Accepted: October 27, 2016

Correspondence: Luís Carvalho Lourenço

Department of Gastroenterology, Hospital Professor Doutor Fernando Fonseca, IC 19, 2720-276, Amadora, Lisbon, Portugal

Tel: +351-91-829-3978, Fax: +21-434-55-66, E-mail: luisclourenco@gmail.com

(cc) This is an Open Access article distributed under the terms of the Creative Commons Attribution Non-Commercial License (http://creativecommons.org/ licenses/by-nc/3.0) which permits unrestricted non-commercial use, distribution, and reproduction in any medium, provided the original work is properly cited. undergone cholecystectomy at another hospital for acute cholecystitis in 2002, complicated with an EHPVT. In addition, he had a history of aortic stenosis, hypertension, and congestive heart failure.

His laboratory values were indicative of leukocytosis $(16.700 / \mathrm{uL})$ and elevated liver enzymes, with a total bilirubin of $8.9 \mathrm{mg} / \mathrm{dL}$.

Abdominal ultrasound revealed dilated intrahepatic bile ducts (IHBD) and CBD, as well as an EHPVT.

The patient was diagnosed with acute cholangitis and treated with antibiotics. Endoscopic retrograde cholangio-pancreatography (ERCP) showed asymmetric stenosis in the middle portion of the CBD (compatible with portal biliopathy type $\mathrm{I}^{2}$ ) and some small stones above it, with dilation of the proximal CBD and IHBD (Fig. 1A). After sphincterotomy and careful stone extraction with Dormia's basket, a 10-Fr plastic stent was placed. Balloon dilation was avoided due to hemobilia risk, which has been reported before. ${ }^{3,4}$

Abdominal computed tomography (CT) scan with contrast revealed a portal cavernoma compressing the middle segment of the CBD and causing the stricture seen during ERCP (Fig. 2).

The patient was not a candidate for portal decompression (transjugular portosystemic shunt was not feasible and he was unfit for surgery due to his advanced age and comorbidities), so progressive biliary plastic stenting was performed every 3 months. However, after one year, there was no improvement in the CBD stenosis and the patient still had elevated liver enzymes and IHBD dilation.

Following failure of progressive plastic stenting, temporary placement of a $80 \times 10-\mathrm{mm}$ fcSEMS (Wallflex ${ }^{\circledR}$; Boston Scientific, Marlborough, MA, USA) was planned. The stent was deployed (Fig. 1B) and removed 6 months later (thereafter) 

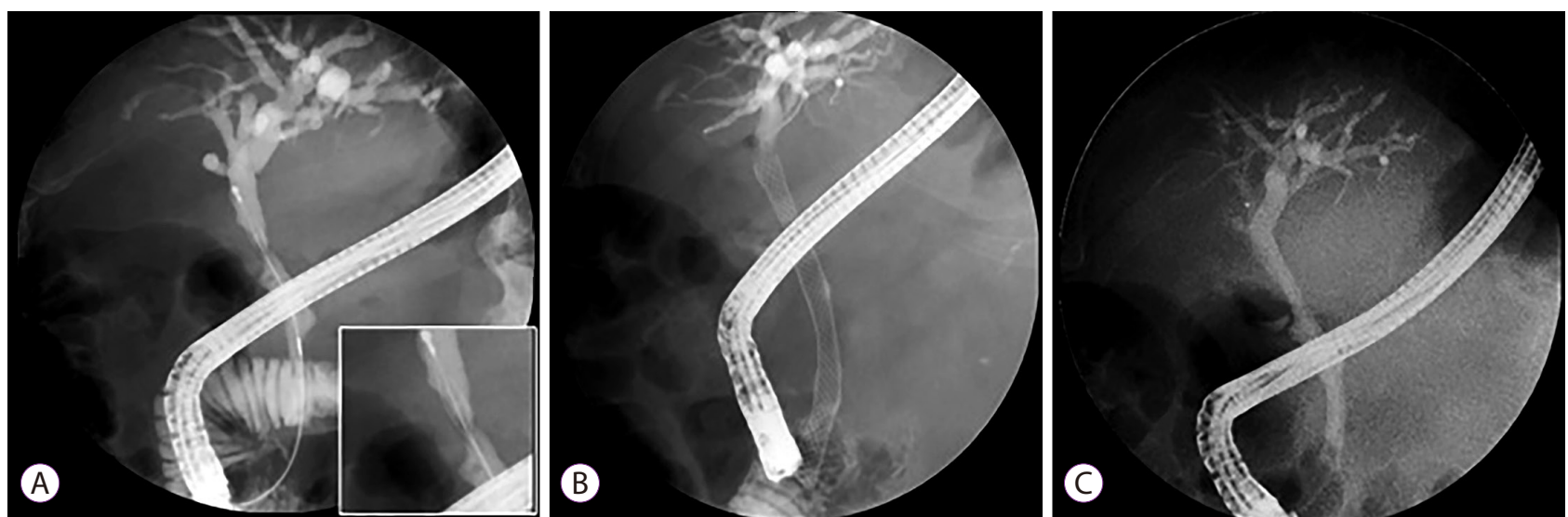

Fig. 1. (A) Cholangiograms obtained during endoscopic retrograde cholangio-pancreatography (ERCP). Asymmetric stenosis in the middle portion of the common bile duct (CBD) ("pseudocholangiocarcinoma sign") with small stones above it and dilation of the proximal biliary ducts. (B) Following failure of progressive plastic stenting, a $80 \times 10-\mathrm{mm}$ fully-covered self-expandable metal stents (fcSEMS) was placed. (C) Stent removal 6 months thereafter revealed improvement in the stenotic segment of the $\mathrm{CBD}$.
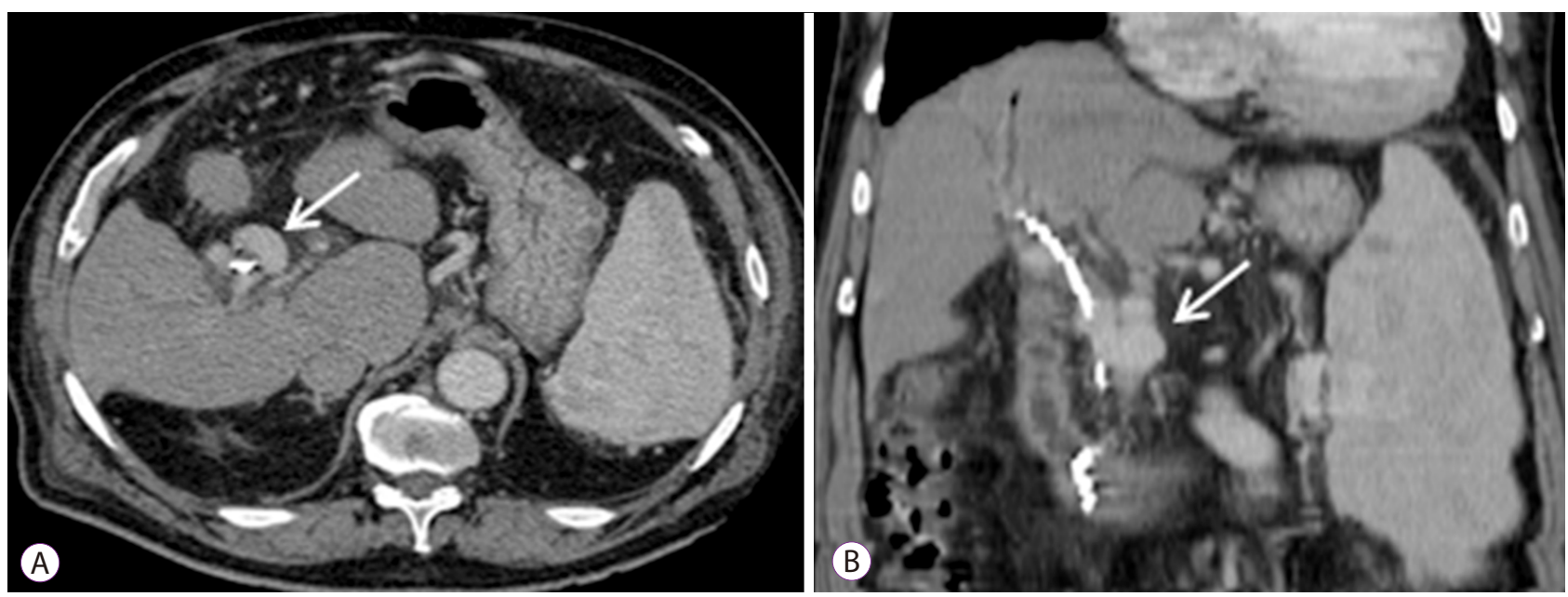

Fig. 2. Abdominal computed tomography (CT) scan with contrast showing typical changes of portal biliopathy including dilated peri-portal venous collaterals with a portal cavernoma, $3 \times 2 \mathrm{~cm}$ (arrow), compressing the middle segment of the common bile duct (CBD) (with plastic stent in place). (A) Axial and (B) Coronal views.

without complications and revealing improvement of the stricture (Fig. 1C).

Liver enzymes became normal, the patient remained asymptomatic, and there was no need for additional endoscopic therapy in the last 12 months.

Currently, data on the endoscopic treatment of portal biliopathy strictures are insufficient. ${ }^{5}$ As for endoscopic therapy, the risk of hemobilia has been studied as a major concern during endoscopic management of PCB. In particular, intra-choledochal varices, masquerading as filling defects, may be the source of bleeding during calculi extraction. Moreover, manipulation of the bile duct also carries a significant risk of complications. Hemobilia has also been reported for other interventions ${ }^{6}$ such as exchange of plastic stents, pneumatic balloon dilatation of stricture, and balloon-occluding cholangiogram during endoscopic management of PCB.
Therefore, surgery is advised for symptomatic cases of PCB, whenever possible.

When surgery is not feasible or the patient is not fit for surgery (which was the case of our patient due to advanced age and comorbidities), plastic stenting is advised. However, it is also important to remember that repeated plastic stenting carries a possible risk of complications and, in refractory strictures, infinite exchanging of stents should ideally be avoided.

There are no guidelines regarding the use of SEMS in symptomatic PCB mainly due to very limited experience. ${ }^{5}$ Moreover, cases managed with a successful and uncomplicated temporary placement of fCSEMS have been rarely reported. ${ }^{7.8}$ Apart from possible migration, as with other strictures, excessive bleeding has been reported during removal of the metallic stent. ${ }^{9}$ However, in this report, a fcSEMS was the first treatment approach, which is not routinely recommended. 
According to the results obtained in our case, we believe temporary placement of fcSEMS might be a good option when surgery is contraindicated, progressive plastic stenting fails, and no episodes of hemobilia have occurred during previous endotherapy. It is reasonable to think that if bleeding has not occurred during plastic stent exchanges, the risk for it to occur during removal of a metal stent is smaller. However, more data are needed regarding this PCB treatment approach.

\section{Conflicts of Interest}

The authors have no financial conflicts of interest.

\section{REFERENCES}

1. Hunt AH. Compression of the common bile-duct by an enlarging collateral vein in a case of portal hypertension. Br J Surg 1965;52:636-637.

2. Dhiman RK, Saraswat VA, Valla DC, et al. Portal cavernoma cholangiopathy: consensus statement of a working party of the Indian national association for study of the liver. J Clin Exp Hepatol 2014;4(Suppl 1):S2S14.

3. Lakhtakia S, Gupta R, Galasso D, et al. Bleeding from portal biliopathy in situs inversus totalis. Endoscopy 2015;47 Suppl 1 UCTN:E335-E336.

4. Sharma M, Ponnusamy RP. Is balloon sweeping detrimental in portal biliopathy? a report of 3 cases. Gastrointest Endosc 2009;70:171-173.

5. Saraswat VA, Rai P, Kumar T, Mohindra S, Dhimany RK. Endoscopic management of portal cavernoma cholangiopathy: practice, principles and strategy. J Clin Exp Hepatol 2014;4(Suppl 1):S67-S76.

6. Mutignani M, Shah SK, Bruni A, Perri V, Costamagna G. Endoscopic treatment of extrahepatic bile duct strictures in patients with portal biliopathy carries a high risk of haemobilia: report of 3 cases. Dig Liver Dis 2002;34:587-591.

7. Oo YH, Olliff S, Haydon G, Thorburn D. Symptomatic portal biliopathy: a single centre experience from the UK. Eur J Gastroenterol Hepatol 2009;21:206-213.

8. Irani S, Baron TH, Akbar A, et al. Endoscopic treatment of benign biliary strictures using covered self-expandable metal stents (CSEMS). Dig Dis Sci 2014;59:152-160.

9. Layec S, D’Halluin PN, Pagenault M, Bretagne JF. Massive hemobilia during extraction of a covered self-expandable metal stent in a patient with portal hypertensive biliopathy. Gastrointest Endosc 2009;70:555556. 